\title{
Exploring Writing Anxiety and Self-Efficacy among EFL Graduate Students in Taiwan
}

\author{
Mei-ching $\mathrm{Ho}^{1}$ \\ ${ }^{1}$ Department of English Instruction, Uinversity of Taipei, Taiwan \\ Correspondence: Mei-ching Ho, Department of English Instruction, University of Taipei, 1, Aiguo W. Rd., \\ Zhongzheng District, Taipei 100, Taiwan. E-mail: mch_clair@utaipei.edu.tw
}

Received: June 30, 2015

Accepted: December 2, 2015

Online Published: December 8, 2015

doi:10.5539/hes.v6n1p24

URL: http://dx.doi.org/10.5539/hes.v6n1p24

\begin{abstract}
This study investigates research writing anxiety and self-efficacy beliefs among English-as-a-Foreign-Language (EFL) graduate students in engineering-related fields. The relationship between the two writing affective constructs was examined and students' perspectives on research writing anxiety were also explored. A total of 218 survey responses from engineering graduate students at Taiwanese universities were analyzed, along with qualitative data from open-ended questions and semi-structured interviews. The findings show that while master's and doctoral students felt a similar moderate level of writing anxiety, senior doctoral students were more self-efficacious about writing research papers in English than their junior counterparts. Overall, students with higher writing self-efficacy felt less apprehensive. Additionally, among the individual variables, experience in writing for publication better predicted writing anxiety and self-efficacy than students' self-reported English proficiency and the number of writing courses taken. The qualitative findings indicated various sources of graduate-level writing anxiety, including insufficient writing skills in English, time constraints, and fear of negative comments. Furthermore, composing different sections of a research paper provoked different levels of anxiety due to the variations in the rhetorical purposes and discourse structures of particular sections. Implications on dealing with research writing anxiety are also discussed.
\end{abstract}

Keywords: writing anxiety, writing self-efficacy, EFL graduate students, academic writing

\section{Introduction}

Graduate-level writing practices across disciplines have gained increasing scholarly attention in recent years. Being able to write various academic genres in English, such as research proposals, conference papers, journal articles, or theses/dissertations, has been one of the most important competences for graduate students in many disciplines (Casanave, 2002; Paltridge, 1997). However, writing academic papers is demanding for Native English Speakers (NES) and can be even daunting for English as a Second/Foreign Language (ESL/EFL) learners. It has been found that students at different educational levels felt apprehensive about writing to varying degrees (Cheng, 2002; Chiang, 2012; Huwari \& Aziz, 2011; Onwuegbuzie, 1997). Previous studies have shown that writing self-efficacy could enhance writing performance and writing anxiety may hinder writing achievement (see Erkan \& Saban, 2011; Sanders-Reio, Alexander, Reio Jr., \& Newman, 2014; Woodrow, 2011). However, most previous studies into writing anxiety and self-efficacy focused on native English speaking students and ESL/EFL learners at secondary or university levels. Relatively little research has examined the influences of graduate-level writing anxiety and self-efficacy as students undertake discipline-specific writing tasks (Lavelle \& Bushrow, 2007). Given the dearth of research on graduate-level writing affective variables in both L1 and L2 settings, this study aims to investigate writing anxiety and self-efficacy among EFL graduate students in Taiwan. Operationally, writing self-efficacy refers to one's confidence in his/her own ability to perform research writing skills. More specifically, the levels and sources of Taiwanese engineering graduate students' research writing anxiety are explored. Adopting a multi-dimensional measure of self-efficacy, this study also investigates students' self-efficacy beliefs concerning different research writing skills.

\section{Literature Review}

\subsection{Writing Anxiety at the Graduate Level}

Since Daly and Miller's (1975) influential work on writing anxiety among Native English Speaking (NES) 
students, a number of studies have been conducted on ESL/EFL students' writing anxiety at secondary and tertiary levels. Writing anxiety refers to an "inherent disposition to anxiety" that can recur when an individual encounters tasks that require a writing component (Daly, 1985; Woodrow, 2011). Previous L2 studies have shown that writing anxiety can negatively influence learners' writing performance. Writing anxiety has also been found to be inversely correlated with writing motivation, self-efficacy, and use of writing strategies (see Erkan \& Saban, 2011; Latif, 2007; Woodrow, 2011). Furthermore, Onwuebguzi and Collins (2001) have identified a link between writing anxiety and academic procrastination. In general, students with a high level of writing anxiety tend to feel demotivated in writing, hold negative attitudes toward writing tasks, produce papers of low quality, have negative impressions about their own writing, and are more likely to avoid situations where writing is required (see Cheng, 2002, 2004; Latif, 2007; Lee \& Krashen, 2002; Onwugubzie, 1997; Sanders-Reio et al., 2014).

Despite numerous studies on writing anxiety at different educational levels, very few have examined the level and impact of writing anxiety on L1 and L2 graduate students. Onwuegbuzie $(1997,1998)$ and Onwuegbuzie and his colleague (2001) are among the few researchers who empirically looked at graduate students' writing anxiety. Onwuegbuzie (1997) found a negative correlation between writing anxiety and research proposal quality of 81 NES graduate students in humanities fields at an American university. Many of his participants felt apprehensive about different aspects of writing, such as idea development, format, organization, and mechanics. Furthermore, students with high writing anxiety tended to submit "under-developed, shorter, less clearly written" research proposals with more grammar and typographical mistakes than those who felt less anxious (Onwuegbuzie, 1997).

In another study, Onwuegbuzie (1998) explored the relationship between writing anxiety and the learning style of 90 American students in social and behavioral science disciplines, using Daly and Miller's (1975) Writing Anxiety Test (WAT). He found that students who preferred to learn in groups seemed to perceive a high level of writing anxiety because many graduate-level writing tasks were usually undertaken by individual students independently, instead of in groups.

In ESL/EFL settings, there has also been scant research on writing anxiety among graduate students across disciplines. Huwari and Aziz (2011), using Daly and Miller's WAT, found that as many as 71 percent of their 103 Jordanian EFL graduate students experienced a high level of writing anxiety, with young doctoral students being more apprehensive than older students. Additionally, they found that dissertation writing was the most anxiety-provoking among the students, compared to writing coursework papers. However, Huwari and Aziz's (2011) findings should be interpreted with caution because many other graduate-level writing tasks (e.g., comprehensive exams and writing for journal publication) were not included for comparison in their survey instrument.

Meng and Tseng (2013) examined the thesis proposal writing process of two Taiwanese EFL master's students in Teaching English to Speakers of Other Languages (TESOL) to identify possible causes of their writing anxiety. They found that writing the literature review section was a major cause of anxiety due to students' perceived lack of ability to logically synthesize a plethora of prior research to make an argument. Based on the interview findings of four Thai EFL doctoral students in applied linguistics, Rungruangthum (2011) also identified several sources of graduate-level writing anxiety, such as time constraints, pressure of getting good grades, professors' expectations, and self-expectation regarding publishing in academic journals.

\subsection{Research on Writing Self-Efficacy}

Since social cognitive theorists (Bandura, 1997, 2006) established the importance of self-efficacy beliefs in learning, a growing body of research has investigated self-efficacy for language learning and has identified its relation to successful learning outcomes. One of the research foci of these studies is writing self-efficacy and its ties to several writing-related variables, such as use of writing strategies, writing anxiety, and writing performance (Erkan \& Saban, 2011; Sanders-Reio et al., 2014). Previous studies have shown that students with high writing self-efficacy tend to write better and have lower writing anxiety than those with low writing self-efficacy (McCarthy, Meier, \& Rinderer, 1985; Pajares \& Valiante, 2006). More recently, writing self-efficacy has also been found to be a more significant predictor of students' writing performance than writing anxiety (Sander-Reio et al., 2014; Woodrow, 2011).

However, it should be noted that most studies on writing self-efficacy surveyed native English speaking students (see Bruning, Dempsey, Kauffman, KcKim, \& Zumbrunn, 2012; Pajares \& valiante, 2006; Pajares, 2007; Shell, Murphy, \& Bruning, 1989; Zimmerman \& Kitsantas, 2007). Relatively few have explored the concept from ESL/EFL students' perspectives. As Woodrow (2011) has already noted, research on self-efficacy for L2 writing 
is scant. Moreover, the research on L1 writing self-efficacy mostly focused on students at the secondary or university levels, extremely few studies, if at all, directly examined writing self-efficacy among NES and ESL/EFL graduate students. In previous studies, writing self-efficacy was only considered as one of the several subscales of research self-efficacy among master's or doctoral students (see Bieschke, Bishop, \& Garcia, 1996; Forester, Kahn, \& Hesson-McInnis, 2004; Kahn \& Scott, 1997; Phillips \& Russell, 1994).

Phillip and Russell (1994), for instance, investigated the research self-efficacy of 125 graduate students in counseling psychology at an American university, using a 33-item Self-Efficacy in Research Measure (SERM). The SERM consisted of four subscales: research design skills, practical research skills, quantitative and computer skills, and writing skills. The level of their graduate students' writing self-efficacy was only medium. Overall, the advanced students (fourth year or beyond) had higher research self-efficacy than the beginning students (first- or second-year graduate students). Phillip and Russell's (1994) findings support predictions derived from Bandura's (1997) self-efficacy theory since advanced graduate students probably had "more experience conducting research and more opportunity to see the research process modeled by faculty and peers" (1994).

In a study on the factor structures of research self-efficacy, Forester, Kahn and Hesson-McInnis (2004) explored the underlying dimensions of three research self-efficacy instruments, used in prior literature, with a large sample of master's and doctoral students in psychology programs in the U.S. Their results indicated four subscales of research self-efficacy, including self-efficacy for data analysis, research integration, data collection, and technical writing. However, only 6 out of the total 58 survey items on their refined instrument assessed technical writing skills (e.g., "Writing the introduction and discussion sections for a research paper for publication;" Writing the introduction and literature review for a thesis") (2004, p. 14). Further studies are needed to tap into the construct of research writing self-efficacy in specific because discipline-specific writing is usually composed of a complex set of skills, such as logical thinking, organizing ideas, searching and using sources, and mastering the linguistic features and the rhetorical discourse conventions, and so on. Forester et al. (2004) also suggest that the assessment of graduate students' self-efficacy for research and writing would assist graduate programs in "[tailoring] the curriculum to address skills that students perceive themselves as lacking at various points in their development" (p. 15).

Although efforts have been made to investigate the relationship between writing anxiety, and writing self-efficacy, little is known about how writing affective factors might influence ESL/EFL graduate students' writing process and performance. Also, most prior research focuses on writing anxiety and self-efficacy associated with general writing tasks, instead of disciplinary writing that usually involves an empirical research component. Furthermore, very little research, if at all, explored the difference in writing anxiety and self-efficacy among graduate students with different training and learning experience in academic writing. Do students who have been trained how to write academic papers in graduate-level writing courses or seminars feel less anxious and more self-efficacious in accomplishing discipline-specific writing tasks? Do students with assistance from advisors in the writing process (e.g., tutoring, editing, and co-authoring) feel less apprehensive and more confident in writing research papers? Do students with more experience in writing for publication experience less writing anxiety? More studies are needed to illuminate these issues. The purpose of this study is to examine the levels of research writing anxiety and self-efficacy among EFL graduate students in engineering-related fields and to look at the relationship between the two affective constructs. More specifically, the present study seeks to address the following four research questions:

1) Do EFL students at different stages of graduate studies perceive different levels of research writing anxiety and self-efficacy?

2) What is the relationship between EFL graduate students' research writing anxiety and their writing self-efficacy?

3) What individual variables (e.g., self-reported English proficiency, experience in writing for publication, and the number of writing courses taken) significantly predict research writing anxiety and self-efficacy?

4) What are students' perspectives on research writing anxiety?

\section{Methods}

\subsection{Participants}

The participants were from different graduate programs/institutes in engineering-related fields (e.g., electrical engineering, computer science and information engineering, chemical engineering, biomedical engineering, civil engineering, etc.) at different universities in northern Taiwan. All the participants were pursuing a master's or a 
doctoral degree at the time of the study. A total of 282 questionnaire responses were collected. However, 19 survey responses contained missing values and 45 of the respondents indicated no experience in writing research genres in English that followed the Introduction, Methods, Results and Discussion (IMRD) structure. As a result, 64 of the survey responses were excluded from analysis. The rest of the 218 survey respondents (153 males and 65 females) consisted of 54 second-year master's students, 97 junior doctoral students, and 67 senior doctoral students. The junior doctoral students were in their first or second year of graduate studies and the senior doctoral students in their third year or above. In Taiwan, finishing a dissertation in English and publishing one or two first-authored articles in academic journals are usually set as part of the degree requirements for most doctoral students in engineering-related fields. In recent years, an increasing number of master's students in many non-English fields are also required to write their master's thesis in English.

\subsection{Instruments}

Two questionnaires, the Research Writing Anxiety Scale (RWAS) and the Research Writing Self-efficacy Index (RWSI), were devised to measure the levels of participants' research writing anxiety and self-efficacy. A background survey with several open-ended questions was also administered to elicit participants' demographic information and to gain more detailed accounts of their concerns and perspectives on writing research papers in English.

Semi-structures interviews were also conducted to better contextualize the participants' responses to the open-ended questions and to supplement the quantitative data. Forty-nine out of the 218 survey respondents indicated their voluntary participation in the interviews. Twenty-five out of the 49 students were then randomly selected and interviewed. Each one-on-one interview lasted approximately 45 to 60 minutes and was audio-recorded for analysis.

\subsubsection{Research Writing Anxiety Scale}

The RWAS was based on Cheng's (2004) Chinese version of Second Language Writing Anxiety Inventory (SLWAI), a 22-item scale with three subscales, including somatic anxiety, cognitive anxiety, and avoidance behavior. Items on somatic anxiety have to do with one's "increased physiological arousal" (e.g., feeling stressed and/or nervous), whereas items on cognitive anxiety and avoidance behavior pertain to an individual's fear of negative evaluation and tendency to avoid L2 writing tasks respectively (Cheng, 2004). The items on the SLWAI, which had been validated to have fair construct validity, were modified specifically for the use with the EFL graduate participants in the current study. For example, research paper was used as a superordinate term to refer to empirical research articles or reports written in the IMRD format. Two professors with experiences in teaching graduate-level writing in ESL/EFL were invited to independently assess the 22 items for readability, clarity, and content validity.

A series of statistical procedures were taken to ensure the reliability of the quantitative data. First, an item analysis was conducted, using an independent-sample t-test to determine whether the mean score of each item for the highest $(25 \%)$ and the lowest $(25 \%)$ participant groups was statistically significant $(\mathrm{p}<.05)$. All the 22 items showed significant difference and were retained. Second, a Principal Components Analysis (PCA) with varimax rotation was used to examine the structure of RWAS. Three components with eigenvalue greater than one were extracted. However, four items were found to have a low coefficient below 0.50. According to Hair, Black, Babin, Anderson and Tatham (2006), the absolute value of factor loadings should be greater than 0.50 and no less than 0.32 . To determine whether the four items should be dropped or retained for follow-up analysis, the "alpha if item deleted" of each of the four items was examined and the Pearson's ratio was also evaluated. Furthermore, the researcher consulted two collegues who had expeiences in teaching English for Academic Purpoes (EAP) and writing academic jouranl papers to further assess the clarity of the four items. After the discussion, the four items were removed as they seemed to be general statements overlapping with other similar but more detailed items. Finally, the remaining 18 items clustered into three distinct factors, accounting for $68.93 \%$ of the variance. This three-factor structure aligned with Cheng's (2004) SLWAI. As shown in Table 1, the reliability coefficients for the three RWAS subscales were $0.83,0.88$, and 0.89 respectively, and the overall Cronbach's alpha was 0.94 , suggesting that the RWAS had fair internal consistency. 
Table 1. The RWAS and RWSI subscales, including item number, reliability coefficients, and sample items

\begin{tabular}{|c|c|}
\hline $\begin{array}{l}\text { Subscales } \\
\text { (Number of items, Cronbach's } \alpha \text { ) }\end{array}$ & Sample items \\
\hline \multicolumn{2}{|l|}{ Overall writing anxiety } \\
\hline \multirow[t]{2}{*}{$\begin{array}{l}\text { Somatic anxiety } \\
(7 \text { items, } \alpha=0.89 \text { ) }\end{array}$} & $\begin{array}{l}\text { My thoughts become jumbled when I write a research paper in } \\
\text { English under time constraint. }\end{array}$ \\
\hline & $\begin{array}{l}\text { I often feel stressed when I have to write a research paper in } \\
\text { English. }\end{array}$ \\
\hline \multirow[t]{2}{*}{$\begin{array}{l}\text { Cognitive anxiety } \\
(8 \text { items, } \alpha=0.88)\end{array}$} & $\begin{array}{l}\text { While writing a research paper in English, I feel apprehensive and } \\
\text { uneasy if I know it will be evaluated or reviewed. }\end{array}$ \\
\hline & $\begin{array}{l}\text { I don't worry at all that the quality of my research paper in English } \\
\text { is worse than my colleagues'. }\end{array}$ \\
\hline \multirow[t]{2}{*}{$\begin{array}{l}\text { Avoidance behavior } \\
(3 \text { items, } \alpha=0.83 \text { ) }\end{array}$} & $\begin{array}{l}\text { I often do my best to excuse myself if asked to write a research } \\
\text { paper in English. }\end{array}$ \\
\hline & $\begin{array}{l}\text { Whenever I have to write a research paper, I often choose to write } \\
\text { it in English. }\end{array}$ \\
\hline \multicolumn{2}{|l|}{ Overall writing self-efficacy } \\
\hline \multirow[t]{2}{*}{$\begin{array}{l}\text { Micro-skills } \\
(8 \text { items, } \alpha=0.84 \text { ) }\end{array}$} & $\begin{array}{l}\text { I can spot grammar mistakes and correct them in my research } \\
\text { paper. }\end{array}$ \\
\hline & $\begin{array}{l}\text { I can properly cite sources whenever I summarize or paraphrase } \\
\text { others' ideas, following the citation format required for my } \\
\text { discipline. }\end{array}$ \\
\hline \multirow[t]{2}{*}{$\begin{array}{l}\text { Macro-skills } \\
(10 \text { items, } \alpha=0.92)\end{array}$} & $\begin{array}{l}\text { I can write up a nice discussion section for a research paper on my } \\
\text { research area. }\end{array}$ \\
\hline & $\begin{array}{l}\text { I can clearly state the importance and purpose of my study in } \\
\text { written English. }\end{array}$ \\
\hline
\end{tabular}

\subsubsection{Research Writing Self-Efficacy Index}

As Pajares and Valiante (2006) suggest, self-efficacy scales need to reflect "an understanding of both the domain under investigation and its different features, as well as of the types of capabilities the domain requires" (p. 162). Following Pajares and Valiante's (2006) suggestion, we developed a 23-item self-efficacy scale with reference to previous studies (Bruning et al., 2013; Jacobs, Opdenacker, \& Van Waes, 2005; Kim, 1996; Pajares, 2007; Sanders-Reio et al., 2014; Woodrow, 2011) to investigate the participants' self-efficacy beliefs regarding research writing. The items were rated on a five-point Likert type scale, ranging from 1 to 5 . A higher rating represented higher self-efficacy.

As the RWSI had not been validated, an exploratory factor analysis with principal-axis factoring and direct oblimin rotation was conducted to ensure its construct validity. Based on the Kaiser Criterion (eigenvalue > 1) and the scree plot, two factors were extracted. It was found that five items had a factor loading lower than 0.50 . Following the same criteria for deleting items in RWAS, the five items were excluded from subsequent analysis. The remaining 18 items, with factor loadings ranging from 0.51 to 0.89 , were retained and accounted for $63.46 \%$ of the variance. The two factors were labeled as micro- and macro-level writing skills. The factor on micro-level writing skills included eight items, assessing participants' confidence level in their ability to use proper grammar, diction, citation forms, and so on. The factor on macro-level writing skills consisted of 10 items, measuring students' perceived competence levels in organizing ideas and writing different sections of a research paper. The internal consistency coefficients of the two factors were 0.84 and 0.92 respectively and the overall alpha was 0.93 , indicating satisfactory reliability (see Table 1 above).

\subsection{Data Analysis}

To analyze participants' responses to the close-ended items in the RWAS and RWSI, a series of statistical analyses were conducted. First, the levels of students' research writing anxiety and self-efficacy were examined 
via descriptive statistics, one-way repeated measures ANOVA, and paired-samples t-test. Second, one-way ANOVA was performed to investigate whether students at different stages of graduate studies perceived significantly different levels of writing anxiety and self-efficacy. Pearson correlation analysis was also used to assess the relationship between the RWAS and the RWSI. Finally, a multiple regression analysis was conducted to investigate the relationship between individual variables, research writing anxiety, and self-efficacy.

All the qualitative data from the open-ended survey questions and interview transcripts were also coded and categorized systematically. Common ideas, relevant to sources of writing anxiety or anxiety-inducing writing difficulties, were grouped into key themes, such as limited vocabulary, grammar issues, lexical choice problems, insufficient rhetorical knowledge of disciplinary research genres, deficient writing self-regulation skill (e.g., poor time management and incompetency in dealing with writer's block), and the difficulties associated with each of the IMRD sections.

To assess the reliability of the coding, the researcher and the two professors, who had previously checked the content validity of the RWAS and RWSI, independently coded $10 \%$ of the qualitative data. The inter-rater reliability was $87 \%$ with a Cohen's kappa value of . 79 in the first round of the norming session. The three coders then discussed the disagreement cases until they reached an agreement. After the discussion, the three coders coded another $10 \%$ of the data, and the resulting kappa of .88 with $96 \%$ of agreement indicates a satisfactory inter-rater reliability. The researcher then proceeded to code the rest of the data.

\section{Results}

\subsection{Research Writing Anxiety and Self-Efficacy among Students at Different Stages of Graduate Studies}

To answer the first research question, it is important to understand to what extent the participants felt anxious and self-efficacious toward writing research papers in general. As shown in Table 2, the overall levels of research writing anxiety and self-efficacy among the participants were modest $(\mathrm{M}=3.06, \mathrm{SD}=0.67$ and $\mathrm{M}=2.93, \mathrm{SD}=$ 0.62 respectively). To examine if there were significant differences among the mean scores of the three RWAS subscales, a one-way repeated measures ANOVA was conducted. Because Mauchly's test revealed that the assumption of sphericity was violated $\left(\chi^{2}(2)=30.23, p=.000\right)$, degrees of freedom were therefore corrected using Huynh-Feldt estimates of sphericity $(\varepsilon=.89)$. The results indicated that significant differences existed among the three research writing anxiety subscales, $\mathrm{F}(1.78,386.79)=58.86, \mathrm{p}=.000$. Post hoc tests using Bonferroni test showed that the mean score of the avoidance behavior subscale $(\mathrm{M}=3.35, \mathrm{SD}=0.70)$ was significantly higher than that of somatic anxiety $(\mathrm{M}=3.01, \mathrm{SD}=0.86)$ and that of cognitive anxiety $(\mathrm{M}=2.82$, $\mathrm{SD}=0.81$ ). These findings suggest that in general, participants tended to avoid writing tasks in English, if given the chances. However, they perceived slightly more motivated arousal than fear of negative feedback while writing research papers in English. The reason why the level of cognitive anxiety was the lowest among the three RWAS subscales may have to do with how students perceived negative feedback on their own writing. As the interview findings revealed, some students were not particularly anxious about receiving negative feedback from their supervisors and seemed to take that as an opportunity to learn about the weaknesses of their writing and get improved.

Table 2. Descriptive statistics of the RWAS, the RWSI, and their subscales

\begin{tabular}{lll}
\hline & $\mathrm{M}$ & $\mathrm{SD}$ \\
\hline Overall writing anxiety & 3.06 & 0.67 \\
Somatic anxiety & 3.01 & 0.86 \\
Cognitive anxiety & 2.82 & 0.81 \\
Avoidance behavior & 3.35 & 0.70 \\
Overall writing self-efficacy & 2.93 & 0.62 \\
Micro-level writing & 2.99 & 0.64 \\
Macro-level writing & 2.88 & 0.59 \\
\hline
\end{tabular}

The results of a paired-samples t-test revealed that students' self-efficacy level for micro-level writing skills (M $=2.99, \mathrm{SD}=0.64)$ was significantly but only slightly higher than that for macro-level skills, $\mathrm{M}=2.88, \mathrm{SD}=$ $0.59, \mathrm{t}(217)=3.92, \mathrm{p}<.001$. 
As Table 3 illustrates, with respect to micro-level writing skills, participants had the lowest efficacy for skills related to language forms and grammar, such as spotting and correcting their own grammar mistakes (Item 4: M $=2.63, \mathrm{SD}=0.88$ ) and rephrasing long and complicated sentences into succinct ones (Item 10: $\mathrm{M}=2.73, \mathrm{SD}=$ $0.89)$. By contrast, participants felt relatively more self-efficacious toward citing and referencing sources in the format required for their field of study (Items 15 and 12 : $\mathrm{M}=3.53, \mathrm{SD}=0.98 ; \mathrm{M}=3.59, \mathrm{SD}=0.95$ ).

Table 3. Descriptive statistics for items in the RWSI subscales

\begin{tabular}{lcc}
\hline Subscale/Item & M & SD \\
\hline Micro-level skills & & \\
4. I can spot grammar mistakes and correct them in my research paper. & 2.63 & 0.88 \\
2. I can correctly apply grammar rules (e.g., singulars, plurals, and verb tenses) & 2.63 & 0.81 \\
when writing research papers in English. & & \\
10. I can rewrite complicated sentences into clear and shorter sentences. & 2.73 & 0.89 \\
6. I can write grammatically correct sentences in English. & 2.86 & 0.85 \\
16. Even if I make punctuation and spelling errors, I am sure I can correct them. & 2.90 & 0.86 \\
7. I can use the right punctuation marks and put them in the right places in my & 3.08 & 0.93 \\
research paper. & & \\
15. I can properly cite sources whenever I summarize or paraphrase others' ideas, & 3.53 & 0.98 \\
following the citation format required for my discipline. & & \\
12. I can present correct referencing information in the format required for my & 3.59 & 0.95 \\
discipline. & & \\
Macro-level skills & & \\
8. I can write a well-organized research paper in English. & 2.54 & 0.87 \\
1. I can write a good introduction for a research paper on my research area. & 2.63 & 0.83 \\
11. I can write up a nice discussion section for a research paper on my research & 2.81 & 0.85 \\
area. & & \\
14. I can write a concise abstract for my research paper in English. & 2.88 & 0.80 \\
17. I can properly paraphrase or summarize others' ideas in my own words in & 2.88 & 0.78 \\
English. & & \\
5. When writing research papers in English, I can get ideas across in a clear & 2.90 & 0.84 \\
manner without getting off topic. & & \\
3. I can write up a good conclusion for a research paper on my research area. & 2.91 & 0.80 \\
13. I can clearly state the importance and purpose of my study in written English. & 3.05 & 0.82 \\
18. I can write a good results section for a research paper on my research area. & 3.10 & 0.87 \\
9. I can clearly describe the methodology or research procedures in English for a & 3.14 & 0.90 \\
research paper. & & \\
\hline
\end{tabular}

With respect to macro-level writing skills, participants felt less self-efficacious toward writing the introduction and the discussion sections (Items 1 and $11: \mathrm{M}=2.63, \mathrm{SD}=0.83 ; \mathrm{M}=2.81, \mathrm{SD}=0.85$ ) than the methods and the results sections (Items 9 and 18: $\mathrm{M}=3.14, \mathrm{SD}=0.90 ; \mathrm{M}=3.10, \mathrm{SD}=0.87$ ). They were also not confident with respect to their ability in composing a concise abstract and properly paraphrasing or summarizing others' ideas (Items 14 and 17: $\mathrm{M}=2.88, \mathrm{SD}=0.80 ; \mathrm{M}=2.88, \mathrm{SD}=0.78$ ). Overall, students did not seem to have much confidence in their macro-level writing skills as only three out of the 10 items received a mean score slightly above three (Items 9, 18, and 13).

To better understand the levels of research writing anxiety and self-efficacy among EFL students at different stages of graduate studies, one-way ANOVA was also conducted. The results in Table 4 show no significant differences in the overall level of research writing anxiety among master's and doctoral students. As for the three 
research writing anxiety subscales, significant differences were only found in the subscale on avoidance behavior, $\mathrm{F}(2,215)=8.23, \mathrm{p}<.001$. Post hoc analyses using Scheffé tests revealed that while no significant difference was found in the avoidance behavior between master's and junior doctoral students, these two groups had significantly higher mean scores in the subscale on avoidance behavior $(\mathrm{M}=3.43, \mathrm{SD}=0.72$ and $\mathrm{M}=3.50, \mathrm{SD}$ $=0.74)$ than their senior counterparts $(\mathrm{M}=3.08, \mathrm{SD}=0.54)$. In addition, no significant differences existed in the subscales of somatic anxiety and cognitive anxiety among the three student groups.

Table 4. One-way ANOVA results for the RWAS and RWSI by academic levels

\begin{tabular}{|c|c|c|c|c|c|c|}
\hline Scale/Subscale & $\mathrm{n}$ & $\begin{array}{l}\text { Academic } \\
\text { level }\end{array}$ & Mean & SD & $\mathrm{F}$ & $\begin{array}{l}\text { Post hoc } \\
\text { (Scheffé) }\end{array}$ \\
\hline \multirow[t]{3}{*}{ Overall writing anxiety } & 54 & MS & 3.15 & 0.66 & & \\
\hline & 97 & $\mathrm{PhD} 1$ & 3.14 & 0.73 & 3.46 & \\
\hline & 67 & $\mathrm{PhD} 2$ & 2.88 & 0.58 & & \\
\hline \multirow[t]{3}{*}{ Somatic anxiety } & 54 & MS & 3.13 & 0.84 & & \\
\hline & 97 & $\mathrm{PhD} 1$ & 3.05 & 0.93 & 1.66 & \\
\hline & 67 & $\mathrm{PhD} 2$ & 2.86 & 0.78 & & \\
\hline \multirow[t]{3}{*}{ Cognitive anxiety } & 54 & MS & 2.89 & 0.80 & & \\
\hline & 97 & PhD1 & 2.85 & 0.82 & 0.84 & \\
\hline & 67 & $\mathrm{PhD} 2$ & 2.72 & 0.81 & & \\
\hline \multirow[t]{3}{*}{ Avoidance behavior } & 54 & MS & 3.43 & 0.72 & & $\mathrm{MS}>\mathrm{PhD} 2$ \\
\hline & 97 & $\mathrm{PhD} 1$ & 3.50 & 0.74 & $8.23 * *$ & $\mathrm{PhD} 1>\mathrm{PhD} 2$ \\
\hline & 67 & $\mathrm{PhD} 2$ & 3.08 & 0.54 & & \\
\hline \multirow[t]{3}{*}{ Overall writing self-efficacy } & 54 & MS & 2.83 & 0.56 & & $\mathrm{MS}<\mathrm{PhD} 2$ \\
\hline & 97 & $\mathrm{PhD1}$ & 2.84 & 0.61 & $6.02 * * *$ & $\mathrm{PhD} 1<\mathrm{PhD} 2$ \\
\hline & 67 & $\mathrm{PhD} 2$ & 3.14 & 0.56 & & \\
\hline \multirow[t]{3}{*}{ Micro-level skills } & 54 & MS & 2.90 & 0.60 & & $\mathrm{MS}<\mathrm{PhD} 2$ \\
\hline & 97 & PhD1 & 2.92 & 0.64 & $4.46^{* *}$ & $\mathrm{PhD} 1<\mathrm{PhD} 2$ \\
\hline & 67 & $\mathrm{PhD} 2$ & 3.18 & 0.57 & & \\
\hline \multirow[t]{3}{*}{ Macro-level skills } & 54 & MS & 2.78 & 0.61 & & $\mathrm{MS}<\mathrm{PhD} 2$ \\
\hline & 97 & PhD1 & 2.79 & 0.66 & $5.77 * * *$ & $\mathrm{PhD} 1<\mathrm{PhD} 2$ \\
\hline & 67 & $\mathrm{PhD} 2$ & 3.10 & 0.60 & & \\
\hline
\end{tabular}

Note. MS: second-year master's students; PhD1: junior doctoral students;

PhD2: senior doctoral students

$* * \mathrm{p}<.01 * * * \mathrm{p}<.001$

By contrast, the mean differences of the overall self-efficacy scale and its two subscales as a function of students' years of graduate studies were all statistically significant, RWSI: $F(2,215)=6.02, p<.001$; micro-level skills: $\mathrm{F}(2,215)=4.46, \mathrm{p}<.01$; macro-level skills: $\mathrm{F}(2,215)=5.77, \mathrm{p}<.001$. The results of the post hoc tests indicated that while the mean difference of the overall research writing self-efficacy between master's students and junior doctoral students was not statistically significant $(\mathrm{M}=2.83, \mathrm{SD}=0.56 ; \mathrm{M}=2.84, \mathrm{SD}=0.61)$, senior doctoral students perceived the highest level of overall self-efficacy among the three student groups $(\mathrm{M}=3.14$, $\mathrm{SD}=0.56)$. Similarly, the mean scores of the two writing self-efficacy subscales were also significantly higher among senior doctoral students than their junior counterparts. However, no significant differences were found in the two writing self-efficacy subscales between master's students and junior doctoral students. These findings seem to imply a threshold in terms of year of graduate study beyond which students' self-efficacy for research writing may increase, although more studies are needed to confirm this. 


\subsection{The Relationship between Research Writing Anxiety and Self-Efficacy}

Table 5 shows the correlations between the variables, which indicate that students' overall level of research writing anxiety significantly negatively correlated with their writing self-efficacy. The magnitude of the correlation was modest, $\mathrm{r}=-0.62, \mathrm{p}<.001$. Significantly negative correlations were also found between the three anxiety subscales and the two self-efficacy subscales with correlation coefficients, ranging from -0.47 to -0.57 . This suggests that the more apprehensive students felt about research writing, the less self-efficacy they perceived regarding both micro- and macro-level research writing skills.

Table 5. Correlations between the RWAS, the RWSI, and their respective subscales

\begin{tabular}{llll}
\hline Scale & OSE & MIS & MAS \\
\hline Overall writing anxiety scale & $-.62^{* * *}$ & $-.58^{* * *}$ & $-.60^{* * *}$ \\
Somatic anxiety & $-.50^{* * *}$ & $-.48^{* * *}$ & $-.48^{* * *}$ \\
Cognitive anxiety & $-.50^{* * *}$ & $-.47^{* * *}$ & $-.49 * * *$ \\
Avoidance behavior & $-.57^{* * *}$ & $-.52^{* * *}$ & $-.55^{* * *}$
\end{tabular}

Note. OSE: Overall Self-Efficacy; MIS: Micro-Level Skills; MAS: Macro-Level Skills

$* * * \mathrm{p}<.001$ (2-tailed)

\subsection{Multiple Regression Analysis of Research Writing Anxiety and Self-Efficacy}

To answer the third research question regarding the individual variables that might have been associated with the levels of research writing anxiety and self-efficacy, a multiple regression analysis was used. More specifically, we examined the relationship among three individual variables (i.e., self-reported English proficiency, experience in writing for publication, and the number of academic writing courses taken), research writing anxiety, and self-efficacy. In the current study, the participants' English proficiency was determined by the scores they received on one of the English proficiency tests (e.g., GEPT, TOEIC, TOEFL, and IELTS). Since students took different English proficiency tests, equivalent scores between different tests were used to determine the participants' self-reported English proficiency. In terms of experience in writing for publications, students were asked to report on whether or not they had written and successfully published papers in English-medium academic journals or conference proceedings. Additionally, students were surveyed on the number of academic writing courses they had taken during their graduate studies.

The results indicated that the bivariate relationships of self-reported English proficiency and experience in writing for publication to research writing anxiety and self-efficacy were significant. By contrast, the bivariate relationship of the number of writing courses taken to both research writing anxiety and self-efficacy was not statistically significant. Furthermore, students' self-reported English proficiency levels and experience in writing for publication were negatively associated with research writing anxiety $(\mathrm{r}=-0.14, \mathrm{p}<.05$ and $\mathrm{r}=-0.29, \mathrm{p}$ $<.001)$ and positively correlated with their writing self-efficacy $(\mathrm{r}=0.16, \mathrm{p}<.05$ and $\mathrm{r}=0.34, \mathrm{p}<.001)$. This suggests that the more experiences students had in writing for publication, the less anxious they were while undertaking research writing tasks.

Table 6. Multiple regression analysis of the three individual variables on research writing anxiety and self-efficacy

\begin{tabular}{llllllll}
\hline & \multicolumn{3}{l}{ Writing Anxiety } & \multicolumn{4}{l}{ Writing Self-efficacy } \\
& \multicolumn{1}{c}{$\left(\mathrm{R} 2=0.18^{* * *}\right)$} & \multicolumn{4}{c}{$\left(\mathrm{R} 2=0.24^{* * *}\right)$} \\
\cline { 2 - 9 } & $\mathrm{B}$ & $\mathrm{SE}$ & $\beta$ & $\mathrm{B}$ & $\mathrm{SE}$ & $\beta$ \\
\hline Self-reported English proficiency & -0.97 & 0.55 & -0.12 & 0.81 & 0.40 & $0.13^{*}$ \\
Experience in writing for publication & -9.40 & 2.29 & $-0.28^{* *}$ & 8.12 & 1.68 & $0.32^{* *}$ \\
The number of writing courses taken & -0.20 & 1.56 & -0.01 & 0.76 & 1.15 & 0.04 \\
\hline
\end{tabular}

${ }^{*} \mathrm{p}<.05, * * \mathrm{p}<.01, * * * \mathrm{p}<.001$ 
As Table 6 illustrates, the combined linear effect of the three individual variables on research writing anxiety was statistically significant (Multiple $\mathrm{R}=.312, \mathrm{p}<.001$ ), with $18 \%$ of the total variation in research writing anxiety being accounted for by the three individual variables. While experience in writing for publication statistically predicted levels of research writing anxiety, students' self-reported English proficiency and the number of writing courses taken did not contribute significantly to the total model. The net effect of experience in writing for publication was the strongest $(\beta=-0.28, \mathrm{p}<.001)$, followed by self-reported English proficiency $(\beta=-0.12)$ and the number of writing courses taken $(\beta=-0.01)$. This suggests that the participants' research writing anxiety were more likely to be resulted from a lack of experience in writing research papers or unfamiliarity with the discipline-specific research genres, instead of insufficient English proficiency. In other words, writing disciplinary research papers itself is anxiety-provoking, regardless of which language students are asked to write the papers in.

As for research writing self-efficacy, the multiple regression analysis results showed that while self-reported English proficiency and experience in writing for publication were significant predictors $(\beta=0.13, \mathrm{p}<.05$ and $\beta$ $=0.32, \mathrm{p}<.001$ respectively), the number of writing courses taken did not significantly predict writing self-efficacy $(\beta=0.04)$. The squared multiple correlation coefficient (R2) was 0.24 , confirmed by a significant $F$ statistic, $\mathrm{F}(3,215)=10.18, \mathrm{p}<.001)$. Overall, experience in writing for publication better predicted writing self-efficacy than self-reported English proficiency. This suggests that when writing research papers in English, the more writing experience students had, the more self-efficacious they were. This finding also support Bandura's (1997) framework that self-efficacy is primarily informed by students' pervious mastery experiences.

\subsection{Students' Perspectives on Research Writing Anxiety}

The analysis of the participants' responses to the open-ended survey questions and interview transcripts revealed that research writing anxiety stemmed from multiple sources. First, insufficient writing proficiency in English, related to incorrect use of grammar and limited vocabulary, was the most commonly mentioned source of research writing anxiety. As many as 61 percent of the participants at the master's or doctoral levels reported limited writing skills as a major source of research writing anxiety. As one master's student in electronics engineering noted,

My English writing is not good. I make a lot of grammar mistakes. When I have to write a paper in English, I always feel under a lot of pressure... And I don't have enough vocabulary to explain complex ideas.

A first-year doctoral student in materials science and engineering also wrote, "I only knew a few sentence patterns and usually wrote long sentences without too much sentence variety". Another master's students mentioned, "I got confused regarding the use of verb tenses when writing different sections of a research paper". Many other students also brought up the issues related to poor lexical choice and repetitive use of certain transitional words. One doctoral student in industrial engineering said, "I used too many hence, therefore, and then. I tried to use other words to connect ideas but I couldn't think of any".

In addition to insufficient writing proficiency in English, concerns about the amount of time needed to finish a research paper emerged as another source of writing anxiety. A quarter of the participants reported that writing under time constraints led to anxiety. As a second-year doctoral student in civil engineering stated,

English is not my native language. It usually takes me more time and effort to write up a paper because I have to translate what I want to say in Chinese to English... A feeling of not being able to get my writing done before the due day always haunted me in the process of writing. I got panic as the deadline approached.

A third-year doctoral student in electrical engineering also mentioned, "compared to making grammar mistakes, time pressure made me more anxious. Because writing a paper in English took me a lot of time, I had less time left for doing experiments".

Other sources of research writing anxiety included problems with idea expression and fear of negative feedback. Many students reported concerns about non-native-like expressions and their monotonous writing style. As one master's student in computer engineering said, "although my grammar and organization are fine, I don't know how to express my ideas in an engaging fashion. My writing is dry and full of long sentences." In addition, fear of negative feedback also emerged as a source of writing anxiety for some students. A second-year doctoral student in mechanical engineering recalled, "I am afraid of getting comments that require me to do major revisions. My supervisor once asked me to rewrite an entire results section because of my poor writing skills. It took me a long time to get the revision done." A master's student in civil engineering also wrote, "I'm always worried that my writing may not meet my supervisor's expectation in terms of quality." However, it should be noted that there were also some participants who were not particularly anxious about getting negative feedback 
and seemed to take it as a learning opportunity. As one fourth-year doctoral student said, "my supervisor's comments helped me see the weaknesses of my paper... as long as I make revisions accordingly, things usually turn out fine".

Another open-ended survey question asked students to indicate which part-genre of a research paper (e.g., the IMRD sections) was the most anxiety-provoking. Excluding missing data and those who provided more than one choice $(9 \%)$, as many as $37 \%$ of the participants reported that writing the introduction section led to the most anxiety, followed by discussion (20\%), abstract (15\%), results (10\%), and methods sections ( $9 \%)$.

The reason why writing the introduction provoked anxiety may have to do with the genre requirements of the section. In many research articles in engineering-related fields, the introduction section usually includes a review of literature. Students would need to synthesize the most relevant literature to identify the gap in previous studies or the research niche and to state the purpose of their research (Swales, 2004). It was found that the process of reviewing and organizing the selected literature purposefully to argue for a need for one's research seemed to cause tremendous anxiety among some master's and doctoral participants. The following excerpt from a second-year doctoral student in mechanical engineering shows a typical reason why students felt apprehensive regarding writing the introduction section:

Reading previous literature in preparation for writing an introduction is difficult and very time-consuming. You need to scan through what you found and select those that are the most relevant. Then you have to read all those articles in detail to identify the contributions and limitations of others' studies to set up a research purpose. It's not that when you have your results ready, you can write a good paper... I think a good research article tells readers why a study needs to be done. To convince readers, you need to know what have been done and be able to to articulate what makes your research special or different from others'.

Twenty percent of the participants indicated that compared to other sections, writing the discussion section caused the most anxiety for two reasons. First, in the discussion section, students would need to refer to other research findings to make comparisons with their own results. Many reported that they were anxious because they did not have a sufficient understanding of prior research to do so. As one second-year doctoral student in environmental engineering noted, "I have to compare my findings with others' and explain what might cause different results. In order to do that, I need to know about other people's studies well. Sometimes, I felt I didn't read enough." Second, some students were concerned about their insufficient ability to clearly explain and interpret the results in English when writing the discussion section. As one master's student in biomedical engineering said during the interview,

I have to explain what caused the sudden increase of radiation, why it increased, how it might affect the human body and the entire experimental design, and so on. Explaining all those clearly in English is very difficult due to my poor writing skills.

In addition, $15 \%$ of the participants reported that abstract writing was the most anxiety-provoking. It was challenging for them to succinctly summarize research purposes, methods, and major findings within a word limit. As one master's students in mechanical engineering recalled, "my supervisor said that an abstract should not be longer than 200 words. I had a hard time summing up my last paper concisely in limited space." In addition, it seemed that writing within a word limit made students apprehensive regardless which language they used to write an abstract. Several students noted that writing an abstract in Chinese was equally anxiety-provoking due to a word limit.

About the same number of participants (9\% and 10\%) reported that writing the methods and results sections resulted in the most anxiety. It was found that students whose research involved complicated or innovative experimental procedures tended to feel apprehensive about writing the methods section. One reason for this was that they were not familiar with the terms associated with some of their research procedures. As a second-year doctoral student in computer engineering said,

When I want to explain how to run a certain computer program, I may not know of the exact words or terms in English to describe certain procedures. For example, one plus one equals two. I may not know of the word "plus" or the term people usually use to explain the function of "plus"... Describing the procedures could become more challenging when our research team used an innovative approach to run the program... I do not know how to describe some of those procedures in English because I did not find any research articles describing a similar approach.

For students who felt apprehensive about writing the results section, insufficient writing skills seemed to be a shared concern. According to a master's students in chemical engineering, "I have to interpret the trends of the 
results in figures. Doing that in English is difficult. And it can even become a problem, especially when there are multiple increases and decreases in the figure and each has different causes".

\section{Discussion}

One of the major findings indicates that the EFL graduate students in engineering-related fields did not perceive a high level of research writing anxiety. However, they were not highly self-efficacious about writing research articles in English, either. One possible reason behind students' moderate level of research writing anxiety may have to do with the different publication requirements for students at different graduate problems. For most master's students in this study, writing and publishing researcher papers in English was usually not set as a degree requirement. Therefore, master's students in this study might not be particularly anxious. In the case of the engineering doctoral students, by contrast, writing a dissertation in English and/or publishing in international journals was usually required. However, it should be noted that many doctoral students may have already known about the degree requirements before entering doctoral programs. Those who decided to pursue a doctoral degree were more likely to be the ones who were determined to take on the challenge of writing research articles in English and thus might be less afflicted by a high level of writing anxiety.

In addition, EFL students at different stages of graduate studies perceived similarly moderate level of research writing anxiety. This finding is not in line with Cheng's (2002) study in which her EFL senior undergraduate participants perceived a higher level of writing anxiety than their freshmen and sophomore counterparts. The disparity may result from the differences between the studies. For instance, the participants in this study were graduate students in engineering-related fields, whereas Cheng's (2002) research involved English-major undergraduates. Another difference lies in the nature of writing tasks students may have encountered. Graduate-level writing in engineering usually involved an empirical research component and was relatively more demanding than the general writing tasks required for undergraduate students in Cheng's (2002) study. Furthermore, due to discipline-specific genre requirements and discourse conventions, research writing tasks might be equally challenging and thus caused anxiety for both junior and senior graduate students. However, it is also likely that students' writing anxiety levels may be affected by the variations in the contextual and individual factors of research writing, such as different departmental requirements, supervisors' expectations, and students' writing proficiency and motivation. Further studies with a longitudinal qualitative design are needed to shed more light on these issues.

The present study also reveals that while senior doctoral students perceived a higher level of research writing self-efficacy than master's and junior doctoral students, no significant differences were found between the later two groups. This finding only partially supports previous research that found a linear increase of self-efficacy according to year of study in terms of foreign language skills (Cubillos \& Ilvento, 2012), general writing skills (Zhang \& Guo, 2012), and information searching skills (Bronstein, 2014). In the absence of research on writing self-efficacy at the graduate level, more studies are needed to investigate the factors behind the fluctuation of writing self-efficacy as a function of educational levels. Additionally, moderate inverse correlations were found between the two writing affective variables and their subscales $(r=-0.47$ to -0.62$)$. This substantiates prior research findings regarding a negative relationship between writing anxiety and self-efficacy among L1 and L2 students at various educational levels (Erkan \& Saban, 2011; Jones, 2008; Pajares, 2007; Sanders-Reio et al., 2014).

Also of note is that students' experience in writing for publication better predicted their research writing anxiety and self-efficacy than their self-reported English proficiency and the number of writing courses taken. Students who had more experiences in writing and successfully publishing papers in academic journals were less anxious and more self-efficacious toward graduate-level writing tasks. These findings corroborate those from Phillips and Russell's (1994) and Kahn and Scott (1997) studies on the relationship between research self-efficacy and research productivity among graduate students in counseling psychology. Although writing self-efficacy is only one of the four subscales in Phillip and Russell's (1994) research self-efficacy inventory, their results also suggest that the advanced graduate students who were in their fourth year or beyond might have more experience in conducting research and writing journal papers and thus felt more self-efficacious than beginning graduate students. These results indirectly suggest that a lack of academic writing experience and/or unfamiliarity with composing discipline-specific academic papers play a significant role in the increase of research writing anxiety and the decrease of writing self-efficacy. Moreover, it is also highly likely that those with more experience in writing for publication may have received better training or more assistance from their dissertation advisors or colleagues, and such training or assistance may thus lower students' writing anxiety. Future research would benefit from a through exploration of the influences of different individual variables on graduate-level research writing anxiety and self-efficacy via various data collection procedures, such as in-depth interviews. 
Based on the participants' self-reports, several sources of research writing anxiety were also identified, including insufficient writing proficiency in English, writing under time constraints, non-native-like expressions, and fear of negative comments. Similar to previous research findings (Latif, 2007; Qian \& Krugly-Smolska, 2008), the qualitative data of this study also reveal students' self-perceived lack of writing proficiency in English as one of the most common reasons behind writing anxiety. However, it should be noted students' self-perceived writing proficiency, mentioned in the qualitative data, may or may not be equal to their overall English proficiency, as reported in the survey instrument. There is a possibility that for beginning graduate students, writing anxiety may mainly result from their unfamiliarity with the discourse conventions and the rhetorical structures of discipline-specific research papers. In other words, most beginning graduate students may feel anxious toward writing a research paper, no matter which language they have to use to write the paper, since they may have never written a discipline-specific research paper before entering graduate school. More studies on these issues are needed to tap into the causes of Taiwanese EFL graduate students' writing anxiety.

In addition, students had different concerns regarding writing different part-genres of a research paper (e.g., the IMRD sections). Although structuring their writing according to the specific purpose of different part-genres provoked anxiety, many participants felt that their lack of writing skills in English was a major stumbling block that made them even more anxious when writing a particular section. Furthermore, it should be noted that students' self-perceived lack of research writing skills implies low self-efficacy. This may be the reason why participants in general did not perceive a high level of writing self-efficacy, as shown in the quantitative analysis. In sum, the various sources of writing anxiety identified in this study suggest the challenges facing engineering graduate students and thus indicate a need to foster not only their research writing skills but also their writing self-efficacy beliefs.

\section{Conclusion}

This study has examined writing anxiety and self-efficacy beliefs among EFL graduate students in various engineering-related fields. Participants' perspectives on writing research papers in English were also explored. Previous research has identified writing anxiety and self-efficacy as significant correlates and predictors of writing outcomes among students at various educational levels (Lee \& Krashen, 2002; Onwuebguzi, 1997; Sanders-Reio et al., 2014; Woodrow, 2011). Understanding graduate-level writing anxiety and self-effiacy is important, given the essential role research writing plays in the academic endeavor of many L1 and L2 students across disciplines.

The findings of this study have some implications for graduate advisors and English for Academic Purposes (EAP) professionals. Because research writing anxiety and self-efficacy are inversely related, enhancing students' self-efficacy beliefs has the potential to ameliorate the intensity of their writing anxiety. As Bandura (1997) suggests, learners' pervious mastery experiences could lead to an increase in self-efficacy. Graduate advisors and faculty could provide more encouraging feedback on students' writing to create a sense of accomplishment early on in their graduate studies. Also, regular advisor-advisee meetings that focus on the writing aspect of students' research can be held to better understand students' writing concerns and to scaffold the development of their research writing strategies. Furthermore, to alleviate anxiety related to L2 writing issues, disciplinary faculty can collaborate with EAP professionals to offer graduate-level writing courses or workshops together. Such writing courses, similar to those suggested in Rubdy's (2005) and Shaw, Moore, and Gandhidasan's (2007) studies, can be tailored to address discipline-specific writing requirements and rhetorical conventions and at the same time to provide more hands-on training on research writing. Such graduate-level writing courses targeting students in non-English disciplines are still rare in many EFL settings, such as Taiwan. More courses of this kind are needed.

Given the design of this study, it is not without limitations. First, the focus on EFL graduate students in engineering-related fields does not allow generalization to students in other fields of study. Replication with a more diverse sample in terms of academic discipline and writing proficiency is needed. Second, the survey instruments used in the study may need further refinement. Future studies could consider modifying the RWSI to include other dimensions of writing self-efficacy, such as self-regulatory skills. Self-efficacy for writing self-regulation pertains to one's perceived confidence in planning, writing time management, and revision (Bruning et al., 2013). Such self-regulatory skills may be also essential for accomplishing graduate-level writing tasks and is worth further investigation. Additionally, concerns have been raised regarding the seemingly double-barreled items in the existing writing self-efficacy survey instruments used in the prior literature. Since very little research, if any, used instruments specifically designed for assessing graduate-level writing self-efficacy, more studies are needed to refine or develop a survey questionnaire, using a larger sample from diverse disciplines and adopting various analytic procedures, such as exploratory and confirmation factor 
analysis. Future research could also trace the causes of writing anxiety and the development of self-efficacy longitudinally to illuminate their positive and negative impacts on graduate students' research and writing productivity and quality.

\section{References}

Bandura, A. (1997). Self-efficacy: The exercise of control. New York, NY: Freeman.

Bandura, A. (2006). Guide to constructing self-efficacy scales. In F. Pajares, \& T. Urdan (Eds.), Self-efficacy beliefs of adolescents (pp. 307-337). Greenwich, CT: Information Age.

Bieschke, K. J., Bishop, R. M., \& Garcia, V. L. (1996). The utility of the research self-efficacy scale. Journal of Career Assessment, 4(1), 59-75.

Bronstein, J. (2014). The role of perceived self-efficacy in the information seeking behavior of library and information science students. The Journal of Academic Librarianship, 40(2), 101-106. http://dx.doi.org/10.1016/j.acalib.2014.01.010

Bruning, R., Dempsey, M., Kauffman, D. F., McKim, C., \& Zumbrunn, S. (2013). Examining dimensions of self-efficacy for writing. Journal of Educational Psychology, 105(1), 25-38. http://dx.doi.org/10.1037/a0029692

Casanave, C. P. (2002). Writing games: Multicultural case studies of academic literacies in higher education. Mahwah, NJ: Lawrence Erlbaum.

Cheng, Y. S. (2002). Factors associated with foreign language writing anxiety. Foreign Language Annals, 35(5), 647-656. http://dx.doi.org/10.1111/j.1944-9720.2002.tb01903.x

Cheng, Y. S. (2004). A measure of second language writing anxiety: Scale development and preliminary validation. Journal of Second Language Writing, 13, 313-335. http://dx.doi.org/10.1016/j.jslw.2004.07.001

Chiang, Y. N. (2012). Perfectionism and EFL writing anxiety in mathematics-and-science-gifted senior high school girls. English Teaching and Learning, 36(1), 53-83. http://dx.doi.org/10.6330/ETL.2012.36.1.02

Cubillos, J. H., \& Ilvento, T. (2012). The impact of study abroad on students' self-efficacy perceptions. Foreign Language Annals, 45(4), 494-511. http://dx.doi.org/10.1111/j.1944-9720.2013.12002.x

Daly, J. A. (1985). Writing apprehension. In M. Rose (Ed.), When a writer can't write: Studies in writer's block and other composing Process Problems (pp. 43-82). London: The Guilford Press.

Daly, J. A., \& Miller, M. D. (1975). The empirical development of an instrument to measure writing apprehension. Research in the Teaching of English, 9, 242-249.

Erkan, D. Y., \& Saban, A. (2011). Writing performance relative to writing apprehension, self-efficacy in writing, and attitudes towards writing: A correlational study in Turkish tertiary-level EFL. Asian EFL Journal, 13(1), 164-192. Retrieved from http://asian-efl-journal.com/PDF/March-2011.pdf\#page=163

Forester, M., Kahn, J. H., \& Hesson-McInnis, M. S. (2004). Factor structures of three measures of research self-efficacy. Journal of Career Assessment, 12(1), 3-16.

Hair, J. F., Black, W. C., Babin, B. J., Anderson, R. E., \& Tatham, R. L. (2006). Multivariate data analysis. New Jersey: Prentice-Hall.

Huwari, I. F., \& Aziz, N. H. A. (2011). Writing apprehension in English among Jordanian graduate students at Universiti Utara Malaysia. Academic Research International, 1(2), 190-198. Retrieved from http://www.savap.org.pk/journals/ARInt./Vol.1(2)/2011(1.2-16).pdf

Jacobs, G., Opdenacker, L., \& Van Waes, L. (2005). A multilanguage online writing center for professional communication: Development and testing. Business Communication Quarterly, 68(1), 8-22.

Jones, E. (2008). Predicting performance in first-semester college basic writers: Revisiting the role of self-beliefs. Contemporary Educational Psychology, 33, 209-238. http://dx.doi.org/10.1016/j.cedpsych.2006.11.001

Kahn, J. H., \& Scott, N. A. (1997). Predictors of research productivity and science-related career goals among counseling psychology doctoral students. The Counseling Psychologist, 25(1), 38-67.

Kim, J. W. (1996). Product and Process Aspects of NES/EFL Students' Persuasive Writing in English: Differences between Advanced and Basic Writers. Texas Papers in Foreign Language Education, 2(2), $19-40$.

Latif, M. A. (2007). The factors accounting for the Egyptian EFL university students' negative writing affect. 
Essex Graduate Student Papers in Language and Linguistics, 9, 57-82. Retrieved from http://www.researchgate.net/publication/238773558

Lavelle, E., \& Bushrow, K. (2007). Writing approaches of graduate students. Educational Psychology, 27(6), 807-822. http://dx.doi.org/10.1080/01443410701366001

Lee, S. Y., \& Krashen, S. (2002). Predictors of success in writing in English as a foreign language: Reading, revision behavior, apprehension, and writing. College Student Journal, 36, 535-543. Retrieved from http://web.ntpu.edu.tw/ lwen/publications/Predictor_of_success_in_writing_in_English_as_a_foreign_lang uage.pdf

Matoti, S., \& Shumba, A. (2011). Assessing the writing efficacy of graduate students at a university of technology in South Africa. Journal of Social Sciences: Interdisciplinary Reflection of Contemporary Society, 29, 109-118.

McCarthy, P., Meier, S., \& Rinderer, R. (1985). Self-efficacy and writing: A different view of self-evaluation. College Composition and Communication, 465-471.

Meng, Z. C., \& Tseng, M. I. (2013). Writing anxiety and EFL graduates' academic writing practices: A case study on two EFL graduate students' learning to write thesis proposals. Paper presented at the 2013 International Conference and Workshop on TEFL and Applied Linguistics, Taoyuan, Taiwan, March 8-9.

Onwuegbuzie, A. J. (1997). Writing a research proposal: The role of library anxiety, statistics anxiety, and composition anxiety. Library and Information Science Research, 19(1), 5-33. http://dx.doi.org/10.1016/S0740-8188(97)90003-7

Onwuegbuzie, A. J. (1998). The relationship between writing anxiety and learning styles among graduates students. Journal of College Student Development, 39(6), 589-598.

Onwugbuzie, A. J., \& Collins, K. M. T. (2001). Writing apprehension and academic procrastination among graduate students. Perceptual and Motor Skills, 92, 560-562. http://dx.doi.org/10.2466/pms.2001.92.2.560

Pajares, F. (2007). Empirical properties of a scale to assess writing self-efficacy in school contexts. Measurement and Evaluation in Counseling and Development, 39(4), 239-249. Retrieved from http://eric.ed.gov/?id=EJ754859

Pajares, F., \& Valiante, G. (2006). Self-efficacy beliefs and motivation in writing development. In C. A. MacArthur, S. Graham, \& J. Fitzgerald (Eds.), Handbook of writing research (pp. 158-170). New York, NY: Guilford Press.

Paltridge, B. (1997). Thesis and dissertation writing: Preparing ESL students for research. English for Specific Purposes, 16(1), 61-70. http://dx.doi.org/10.1016/S0889-4906(96)00028-2

Phillips, J. C., \& Russell, R. K. (1994). Research self-efficacy, the research training environment, and research productivity among graduate students in counseling psychology. The Counseling Psychologist, 22(4), 628-641.

Qian, J., \& Krugly-Smolska, E. (2008). Chinese graduate students' experiences with writing a literature review. TESL Canada Journal, 26(1), 68-86. Retrieved from http://www.teslcanadajournal.ca/index.php/tesl/article/view/391

Rubdy, R. (2005). A multi-thrust approach to fostering a research culture. ELT Journal, 59, $277-286$. http://dx.doi.org/ 10.1093/elt/cci056

Rungruangthum, M. (2011). Writing anxiety: EFL graduate students writing research papers in English. Journal of English Studies, $\quad 6, \quad$ Retrieved from http://www.tci-thaijo.org/index.php/JournalEnglishStudies/article/view/21854

Sanders-Reio, Alexander, J. P., Reio Jr., T. G., \& Newman, I. (2014). Do students' beliefs about writing relate to their writing self-efficacy, apprehension, and performance? Learning and Instruction, 33, 1-11. http://dx.doi.org/10.1016/j.learninstruc.2014.02.001

Shaw, J., Moore, P., \& Gandhidasan, S. (2007). Educational acculturation and academic integrity: Outcomes of an intervention subject for international graduate public health students. Journal of Academic Language and Learning, 1(1), A55-A67. Retrieved from http://ro.uow.edu.au/hbspapers/2052/

Shell, D. F., Murphy, C. C., \& Bruning, R. H. (1989). Self-efficacy and outcome expectancy mechanisms in reading and writing achievement. Journal of Educational Psychology, 81(1), 91. 
Swales, J. (2004). Research genres: Exploration and applications. Cambridge: Cambridge University Press.

Woodrow, L. (2011). College English writing affect: Self-efficacy and anxiety. System, 29, 510-522. http://dx.doi.org/10.1016/j.system.2011.10.017

Zhang, Y., \& Guo, H. (2012). A study of English writing and domain-specific motivation and self-efficacy of Chinese EFL learners. Journal of Pan-Pacific Association of Applied Linguistics, 16(2), 101-121. Retrieved from http://paal.kr/download/16_2_07_Yanyan Zhang and Hui Guo1.pdf

Zimmerman, B. J., \& Kitsantas, A. (2007). A writer's discipline: The development of self-regulatory skill. In S. Hidi, \& P. Boscolo (Eds.), Motivation and writing: Research and school practice (pp. 51-69). New York, NY: Kluwer.

\section{Copyrights}

Copyright for this article is retained by the author(s), with first publication rights granted to the journal.

This is an open-access article distributed under the terms and conditions of the Creative Commons Attribution license (http://creativecommons.org/licenses/by/3.0/). 